\title{
O CONSUMO DE ÁLCOOL ENTRE OS ESTUDANTES DO CURSO DE MEDICINA: REVISÃO BIBLIOGRÁFICA
}

\section{ARTIGO DE REVISÃO}

SPAZIANI, Amanda Oliva ${ }^{1}$

NUNES, Marcelo Ferreira Manna ${ }^{2}$

DINIZ, Frederico Soares ${ }^{3}$

VIEIRA, Patrícia Zanatta Antunes ${ }^{4}$

LIMA, Paulo Henrique De Souza ${ }^{5}$

FURTADO, Vitória Luvisari ${ }^{6}$

SANTOS, Flávio Henrique Nuevo Benez Dos ${ }^{7}$

SPAZIANI, Amanda Oliva. Et al. O consumo de álcool entre os estudantes do curso de medicina: Revisão bibliográfica. Revista Científica Multidisciplinar Núcleo do Conhecimento. Ano 04, Ed. 08, Vol. 02, pp. 140-148. Agosto de 2019. ISSN: 2448-

\footnotetext{
${ }^{1}$ Graduanda em Medicina pela Universidade Brasil - Fernandópolis, Brasil.

${ }^{2}$ Graduando em Medicina pela Universidade Brasil - Fernandópolis, Brasil.

${ }^{3}$ Graduando em Medicina pela Universidade Brasil - Fernandópolis, Brasil.

${ }^{4}$ Graduanda em Medicina pela Universidade Brasil - Fernandópolis, Brasil.

${ }^{5}$ Graduando em Medicina pela Universidade Brasil - Fernandópolis, Brasil.

${ }^{6}$ Graduanda em Medicina pela Universidade Brasil - Fernandópolis, Brasil.

${ }^{7}$ Médico Especialista em Ortopedia e Traumatologia pela Universidade São Francisco - Bragança Paulista, Brasil. Especialista em Medicina Física e Reabilitação pela Rede Lucy Montoro de São Paulo, Brasil. Mestre em Ciências da saúde pela Universidade São Francisco - Bragança Paulista, Brasil.
} 
0959, Link de acesso: https://www.nucleodoconhecimento.com.br/saude/consumode-alcool

\section{RESUMO}

Objetivo: O estudo tem como objetivo analisar os dados de forma comparativa de três estudos realizados sobre o consumo de álcool por estudantes de medicina. Metodologia: Trata-se de um estudo de revisão bibliográfica. Para confecção deste estudo, utilizou-se como técnica a forma comparativa, para tal foram utilizados, como referência central, dados extraídos de três estudos. Conclusão: Apenas 5,7\% da amostra encontram-se nas Zonas III e IV, 66,8\% do total ingerem álcool, dado esse considerado preocupante. Por meio da análise desses dados, é possível concluir que é importante conscientizar os estudantes de medicina sobre os riscos da ingestão de álcool.

Palavras-chave: Consumo de álcool, consumo de álcool por estudantes de medicina, consumo excessivo de álcool.

\section{INTRODUÇÃO}

O estudante após a introdução na vida universitária inicia um processo cheio de mudanças em sua forma de viver, onde o meio leva ao consumo de álcool. A consumação de forma abusiva de álcool leva a várias consequências negativas para a saúde física, mental e para sociedade ${ }^{1,2}$. O alcoolismo tem a capacidade de afetar a conduta humana em vários aspectos, sendo considerado um problema de saúde pública, constituindo-se em uma patologia hereditária que se expressa de forma variada em seus descendentes ${ }^{3}$.

A bebida alcoólica auxilia nas relações sociais, no entanto, causa consequências negativas para os indivíduos que consomem excessivamente, haja vista seu envolvimento em acidentes de trânsito, quedas, atropelamentos, violência dentro do ambiente familiar e nas ruas, problemas sociais, de saúde física e psíquica. A 
ocorrência maior de eventos como brigas, vandalismo, ausência no trabalho podem ser associados por esse consumo ${ }^{4}$.

O álcool pode ser considerado uma bebida rica ingerida durante hábitos sociais, culturas e religiosos, mas é uma droga que causa efeitos farmacológicos e tóxicos atuando na mente e em todos os órgãos do corpo humano. Mesmo com esses efeitos negativos, a sociedade incentiva seu consumo por encará-la como algo lícito e diferente das outras drogas 5 .

Mesmo com a ingestão de álcool de forma moderada, a mesma vem sendo considerada como algo normal na maioria das culturas, o consumo excessivo não costuma ser aceito. Segundo a Organização Mundial de Saúde (OMS) o álcool é a substância psicoativa mais ingerida no mundo ${ }^{6}$. No Brasil o álcool também é uma das drogas mais consumidas, chega a ser consumido por quase $70 \%$ da população e é o grande causador de acidentes graves e mortes violentas ${ }^{7}$.

O consumo de álcool por alunos universitários é uma prática frequente e que muitas vezes ocorre desde o início da vida acadêmica. A universidade representa novas realidades e possibilidades, além de gerar sentimentos de independência, isso tudo faz com que os jovens busquem novas experiências, incluindo a adesão ao etilismo ${ }^{8}$.

\section{OBJETIVO}

Considerando todas essas informações, esse estudo objetiva analisar os dados de forma comparativa de três estudos realizados sobre o consumo de álcool por estudantes de medicina.

\section{METODOLOGIA}

Trata-se de um estudo de revisão bibliográfica. Para confecção deste estudo, utilizouse como técnica a forma comparativa, para tal foram utilizados, como referência central, dados extraídos de três estudos. As pesquisas ocorreram no período compreendido entre 27 de setembro de 2015 e 10 de outubro de 2015 e foi realizada 
por meio das palavras-chaves: consumo de álcool, consumo de álcool por estudantes de medicina e consumo excessivo de álcool.

O primeiro estudo foi realizado na Universidade Federal do Maranhão em 2010 e foram avaliados 337 estudantes do primeiro ao décimo primeiro período de medicina.

O segundo estudo foi realizado na Universidade Federal do Tocantins em 2013 e foram avaliados 306 estudantes de todos os períodos de medicina.

O terceiro estudo foi realizado em duas universidades, sendo uma pública e uma privada do estado de Minas Gerais em 2009 e foram avaliados 571 estudantes do primeiro ao oitavo período de medicina.

Nos três estudos, foi aplicado o Teste para Identificação de Problemas Relacionados ao Álcool (Audit) na versão autoaplicável, esse teste é composto por dez questões sobre o consumo de álcool no último ano. Foi desenvolvido pela OMS e tem como objetivo identificar pessoas com consumo de risco, uso nocivo e dependentes de álcool $^{9}$. As três primeiras questões verificam o uso perigoso de álcool, as três seguintes avaliam os sintomas relacionados com a dependência e as quatro últimas ao uso prejudicial do álcool. Esse teste classifica os indivíduos em quatro zonas de risco, a I que varia de 0 a 7 pontos, a II de 8 a 15 pontos, a III de 16 a 19 pontos e a IV de 20 a 40 pontos. Os riscos aumentam proporcionalmente as pontuações ${ }^{10}$.

A primeira zona refere-se a indivíduos que podem obter benefícios com acesso a orientações sobre o consumo de álcool. A segunda zona refere-se a indivíduos que embora não estejam exibindo problemas, podem futuramente apresentar. A terceira zona refere-se a indivíduos que apresentam problemas e mantem uso regular excedendo limites. A quarta zona refere-se a um grupo de intenso risco ${ }^{11}$.

Para realização da análise e posteriormente a síntese dos artigos, foram construídas tabelas que consideraram os seguintes aspectos: nome dos autores e ano de publicação, amostragem, metodologia, resultados, distribuição e frequência. 


\section{RESULTADOS E DISCUSSÃO}

Foram incluídos 3 artigos para análise e discussão (Tabela 1 e 2). O total de estudantes abrangidos é de 1214.

Tabela 1. Artigos incluídos na revisão de acordo com autor, ano de publicação, amostragem, metodologia e resultados.

\begin{tabular}{|c|c|c|c|}
\hline $\begin{array}{l}\text { Autoria/Ano de } \\
\text { publicação }\end{array}$ & Amostra & Metodologia & Resultados \\
\hline $\begin{array}{l}\text { Barbosa et al. } \\
(2013)\end{array}$ & 337 & Transversal & $\begin{array}{l}\text { - } 120 \text { estudantes não fazem uso } \\
\text { de bebida alcoólica; } \\
\text { - } 217 \text { estudantes consomem } \\
\text { bebida alcoólica; } \\
\text { - } 121 \text { estudantes: Zona I } \\
\text { - } 83 \text { estudantes: Zona II } \\
\text { - } 10 \text { estudantes: Zona III } \\
\text { - } 3 \text { estudantes: Zona VI }\end{array}$ \\
\hline $\begin{array}{l}\text { Ribeiro et al. } \\
(2015)\end{array}$ & 306 & Transversal & $\begin{array}{l}\text { - } 74 \text { estudantes não fazem uso } \\
\text { de bebida alcoólica; } \\
\text { - } 232 \text { estudantes consomem } \\
\text { bebida alcoólica; } \\
\text { - } 118 \text { estudantes: Zona I } \\
\text { - } 88 \text { estudantes: Zona II } \\
\text { - } 15 \text { estudantes: Zona III } \\
\text { - } 11 \text { estudantes: Zona VI }\end{array}$ \\
\hline
\end{tabular}




\begin{tabular}{|c|c|c|c|}
\hline Rocha et al. (2011) & 571 & Transversal & $\begin{array}{l}\text { - } 208 \text { estudantes não fazem uso } \\
\text { de bebida alcoólica; } \\
\text { - } 363 \text { estudantes consomem } \\
\text { bebida alcoólica; } \\
\text { - } 272 \text { estudantes: Zona I } \\
\text { - } 84 \text { estudantes: Zona II } \\
\text { - } 7 \text { estudantes: Zona III } \\
\text { - Não houve estudantes na } \\
\text { Zona VI }\end{array}$ \\
\hline
\end{tabular}

Fonte: (próprio autor)

Tabela 2: Distribuição da quantidade e da frequência do consumo de bebidas alcoólicas entre os acadêmicos de Medicina.

\begin{tabular}{|l|l|l|l|l|l|l|l|l|}
\hline Consumo & $\begin{array}{l}\mathbf{1}^{\circ} \\
\text { estudo }\end{array}$ & $\begin{array}{l}\text { 2. } \\
\text { estudo }\end{array}$ & $\begin{array}{l}\text { \% } \\
\text { estudo }\end{array}$ & & $\begin{array}{l}\text { Total } \\
\text { amostrado }\end{array}$ & $\%$ \\
\hline Não bebem & 120 & 35,6 & 74 & 24,2 & 208 & 36,4 & 402 & 33,2 \\
\hline Bebem & 217 & 64,4 & 232 & 75,8 & 363 & 63,6 & 812 & 66,8 \\
\hline Zona I & 121 & 55,8 & 118 & 50,9 & 272 & 74,8 & 511 & 62,9 \\
\hline Zona II & 83 & 38,2 & 88 & 38,0 & 84 & 23,3 & 255 & 31,4 \\
\hline Zona III & 10 & 4,6 & 15 & 6,4 & 7 & 1,9 & 32 & 4,0 \\
\hline Zona IV & 3 & 1,4 & 11 & 4,7 & 0 & 0 & 14 & 1,7 \\
\hline Total & $\mathbf{3 3 7}$ & $\mathbf{1 0 0}$ & $\mathbf{3 0 6}$ & $\mathbf{1 0 0}$ & $\mathbf{5 7 1}$ & $\mathbf{1 0 0}$ & $\mathbf{1 2 1 4}$ & $\mathbf{1 0 0}$ \\
\hline amostrado & & & & & & & & \\
\hline
\end{tabular}

Fonte: (próprio autor - adaptado)

Considerando o total amostrado nos 3 estudos, totalizado por 1214 alunos de medicina, destaca-se que apenas no terceiro estudo os pesquisadores ouviram 
estudantes de escola pública e privada de forma mista. Deste total de alunos, 602 $(49,5 \%)$ eram do sexo feminino e $605(49,8 \%)$ eram do sexo masculino, sendo que 7 pacientes não responderam a informação sobre o gênero.

Observou-se que a menor parte dos estudantes declararam não ingerir bebidas alcoólicas, totalizando $33,2 \%$ do total, logo se conclui que a maioria declarou ingerir bebidas, totalizando $66,8 \%$ da amostra. Essa tendência foi evidenciada e corroborada nos 3 estudos em análise. No estudo de Barbosa et al. (2013), traz que a maior parte se encaixa na Zona I, ou seja, bebem com padrão de baixo risco ou não bebem. No entanto, 44,2\% estão nas Zonas II, III e IV, que são classificações consideradas com nível possivelmente deletério à saúde ${ }^{12}$.

Um fato a ser destacado nos resultados das pesquisas e descrito na coluna da frequência do total amostrado, é a maior concentração daqueles que ingerem bebidas nas classificações das zonas I e II, totalizando $94,3 \%$, ou $62,9 \%$ e $31,4 \%$ respectivamente.

É importante que, mesmo aqueles que ingerem bebidas alcoólicas, estejam representados em sua maioria, na Zona I ou no máximo na Zona II, localização estas que geram menor prejuízo aqueles que de alguma forma ingerem bebidas alcoólicas. Esse fato é corroborado por outro estudo, como destacam Rocha et al. (2011) quando asseveram que a primeira zona se refere a indivíduos que podem se beneficiar com informações sobre o consumo de álcool. Enquanto que a segunda zona se refere a indivíduos que embora não estejam ocasionando problemas, podem ocasionar, praticar violências podendo causar lesões, problemas legais, sociais e com a ocorrência quadros de intoxicação ter o desempenho reduzido ${ }^{11}$.

O estudo evidenciou o menor enquadramento do total amostrado nas Zonas III e IV, totalizando $5,7 \%$ dos pesquisados, destes $4,0 \%$ estão concentrados na Zona III, enquanto apenas $1,7 \%$ estão classificados na Zona IV, fato esse relevante nas pesquisas realizadas, visto que para Rocha et al. (2011) essas zonas são realmente preocupantes, pois a terceira zona acena para pessoas que se mostram problemáticas e mantêm uso continuo ultrapassando limites desejáveis de ingestão 
de álcool, enquanto o autor preconiza ainda que aqueles que se enquadram na Zona IV devem procurar ajuda de profissionais especializados, pois esse grupo enquadrase num grupo de risco intenso ${ }^{11}$.

\section{CONCLUSÃO}

Apenas 5,7\% da amostra encontram-se nas Zonas III e IV, 66,8\% do total ingerem álcool, dado esse considerado preocupante. Por meio da análise desses dados, é possível concluir que é importante conscientizar os estudantes de medicina sobre os riscos da ingestão de álcool.

Considerado um agente psicoativo perigoso e prejudicial para o organismo, o álcool contínua com o consumo ainda amplamente aceito na sociedade. É necessário comprometimento social e governamental acerca do consumo de álcool, principalmente dentre a população jovem, visto que essa substância pode causar severo prejuízo a essa faixa etária.

\section{REFERÊNCIAS}

1. Chassin, L; Pitts, S.C.; Prost, J. Binge drinking trajectories from adolescent to emerging adulthood in a high-risk sample: predictors a substance abuse outcome. J Consult Clin Psychol. 2002;70:67-78.

2. Stempliuk, V.A.; Barroso, L.P.; Andrade, A.G.; Nicastri, S.; Malbergier, A. Comparative study of drug use among undergraduate at the university of São Paulo - São Paulo campus in 1996 and 2001. Rev Bras Psiquiatr. 2005;27:18593.

3. Pierobon, M.B.M.; Hazrati, S.; Jacobsen, K.H. Consumo de álcool e violência entre adolescentes argentinos. J. Pediatr. (Rio J.), Porto Alegre, v. 89, n. 1, p. 100-107, Feb. 2013.

4. Anjos, K.F.; Santos, V.C.; Almeida, O.S. Caracterização do consumo de álcool entre estudantes do ensino médio / Characterization of the consumption of alcoholic beverages among senior high school students / Caracterización del 
consumo de alcohol entre estudiantes de la enseñanza media; Rev. baiana saúde pública;36(2), abr.-jun. 2012.

5. Marques, N.F.B.; Maciel, E.A.F.; Barbosa, F.I. Consumo de álcool pelos acadêmicos do curso de enfermagem de uma instituição de ensino superior. vista de enfermagem do Centro-Oeste Mineiro / Universidade Federal de São João Del-Rei, Campus Centro Oeste Dona Lindu.- 2(2):159-165, 2012.

6. Galduróz, J.C.F.; Caetano, R. Epidemiology of alcohol use in Brazil. Rev Bras Psiquiatr. 2004; 26(supl.2): 3-4.

7. Ferreira, M.P.; Laranjeira, R. Dependência de substâncias psicoativas. In: Ito L, org. Terapia cognitivo-comportamental para transtornos psiquiátricos. Porto Alegre: Artes Médicas; 1998.

8. Rocha, F.I.F.; Cardoso, F.C. O consumo de álcool entre os adolescentes na cidade de Araxá: uma abordagem sociológica e jurídica. Revista Jurídica UNIARAXÁ, Araxá, v. 16, n. 15, p. 140-162, ago. 2012.

9. Babor, T.F.; Higgins-Biddle, J.C.; Saunders, J.B.; Monteiro, M.G. The Alcohol Use Disorders Identification Test. Guidelines for use in primary care. Geneva; 2001. WHO.

10. Ribeiro, G.F.F.; França, V.M.; Faria, R.L.B.C.; Cuellar, P.M.G.; Martins, M.L.B. Álcool: uso por estudantes de medicina da Universidade Federal do Tocantins. Rev. Cereus, v. 7, n. 1 (2015) - ISSN 2175-7275. Gurupi (TO).

11. Rocha, L.A.; Lopes, A.C.M.M.F.; Martelli, D.R.B.; Lima, V.B.; Martelli-Júnior, H. Consumo de álcool entre estudantes de faculdades de Medicina de Minas Gerais, Brasil. Rev. bras. educ. med., Rio de Janeiro , v. 35, n. 3, p. 369375, Sept. 2011.

12. Barbosa, F.L.; Barbosa, R.L.; Barbosa, M.C.L.; Aguiar, D.L.; Figueiredo, I.A.; Ribeiro, A.C.; Castro, I.T.C. Uso de álcool entre estudantes de medicina da Universidade Federal do Maranhão. Rev. bras. educ. méd, v. 37, n. 1, p. 89-95, 2013.

Enviado: Julho, 2019.

Aprovado: Agosto, 2019. 